\title{
DILATATION OF THE RESTING POSTERIOR URETHRA IN SPINAL CORD INJURY PATIENTS
}

\author{
By J. Nordling, M.D., K. P. Olesen, M.D. and T. Hald, M.D. \\ Urological Laboratory, Department of Urology and Department of Radiology, \\ Herlev Hospital, University of Copenhagen, DK 2730 Herlev, Denmark
}

\begin{abstract}
In 26 patients with detrusor-sphincter dyssynergia after a spinal cord injury the resting posterior urethra at cystography was found either closed as in normal subjects or open to a varying degree. Highest intravesical pressure measured at cystometry during uninhibited detrusor contraction was statistically significantly related to the degree of dilatation of the resting posterior urethra. An even higher correlation coefficient was found between the dilatation of the resting posterior urethra and an arbitrary score calculated on the basis of highest cystometric pressure and duration of disease since spinal cord injury. The possible importance of this finding in relation to incontinence after urethral sphincterotomy is discussed.
\end{abstract}

Key words: Neurogenic bladder; Urethra; Cystography; Detrusor-sphincter dyssynergia; Cystometry.

\section{Introduction}

IN a series of patients with spinal cord injuries examined for bladder disorders, voiding cysto-urethrography revealed inexplicable variations in the configuration of the posterior urethra, when the bladder was at rest. Some cases showed an entirely open urethra down to the external sphincter, while others were completely closed and others again displayed a downwards pointed beak of contrast medium from a partly open internal urethral orifice. Since all patients suffered from upper motor neuron lesions with detrusor-sphincter dyssynergia one explanation for the varied configuration of the posterior urethra might be a deterioration of this part of the urethra caused by long-lasting strain from the high-pressure detrusor working against the contracted sphincter. It has previously been shown that the posterior urethra is widely dilated during voiding with detrusor-sphincter dyssynergia (Madersbacher, I977), but the configuration of the posterior urethra with the bladder at rest does not seem to have been reported.

\section{Material and Method $^{1}$}

The records of 26 consecutive patients with spinal cord injuries without previous surgery of the lower urinary tract were studied. There were 20 males and six females. The neurological level of the spinal cord injury was nine cervical, ten thoracic and seven lumbar. Three cervical, eight thoracic and six lumbar lesions were complete, the rest incomplete. The mean age was 35 years with a range from $19-68$ years.

All patients had been examined by:

I. $\mathrm{CO}_{2}$-cystometry during filling of the bladder at a rate of $200 \mathrm{ml} /$ minutes

1 Methods, definitions and units conform to the standards proposed by the International Continence Society except where specifically noted. 
combined with electromyography from the urethral sphincter using an intraurethral ring electrode mounted on an $\mathrm{I} 8 \mathrm{~F}$ Foley bag catheter (Nordling et al., I978).

2. Urodynamic evaluation with simultaneously bladder and rectal pressure measurement, electromyography from the anal sphincter with a coaxial needle electrode and urinary flow recording (Frimodt-Møller \& Hald, 1977).

3. Cysto-urethrography in the lateral projection with simultaneous intravesical pressure measurement through a transurethrally positioned $5 \mathrm{~F}$ catheter (Olesen \& Walter, I977).

Highest intravesical pressure during uninhibited detrusor contraction measured at cystometry was used as an expression of detrusor strength. As the $\mathrm{CO}_{2}$ cystometer only registers pressures lower or equal to $100 \mathrm{~cm} \mathrm{H}_{2} \mathrm{O}$, the patients were divided into three groups (Table I). Group I with intravesical pressures below or equal to $50 \mathrm{~cm} \mathrm{H}_{2} \mathrm{O}$, group 2 with pressures exceeding $50 \mathrm{~cm}$ $\mathrm{H}_{2} \mathrm{O}$ but lower or equal to $100 \mathrm{~cm} \mathrm{H}_{2} \mathrm{O}$ and group 3 with pressures exceeding IOO $\mathrm{cm} \mathrm{H} \mathrm{H}_{2} \mathrm{O}$. Because it could be suspected that it would take a certain time to develop a dilated posterior urethra the patients were also divided into three groups according to duration of disease (Table I). Group I : patients investigated less than I year after injury; group 2: patients investigated between I and 2 years after injury; and group 3: patients investigated more than 2 years after injury.

\section{TABLE I}

Patients divided into cystometric and duration groups based on highest intravesical pressure during uninhibited detrusor contraction and time since spinal cord injury

\begin{tabular}{|c|c|c|c|}
\hline \multirow[t]{2}{*}{ Cystometric group } & \multicolumn{3}{|c|}{$\begin{array}{c}\text { Time since spinal cord injury } \\
\text { Duration group }\end{array}$} \\
\hline & $\begin{array}{c}\text { I } \\
<\text { I year }\end{array}$ & $\begin{array}{l}2 \\
I-2 \\
\text { years }\end{array}$ & $\begin{array}{l}3 \\
>2 \text { years }\end{array}$ \\
\hline I. max. pressure $\leqq 50 \mathrm{~cm} \mathrm{H}_{2} \mathrm{O}$ & - & - & I \\
\hline 2. max. pressure $>50 \leqq 100 \mathrm{~cm} \mathrm{H}_{2} \mathrm{O}$ & 3 & 3 & 4 \\
\hline 3. max. pressure $>100 \mathrm{~cm} \mathrm{H}_{2} \mathrm{O}$ & 3 & 2 & IO \\
\hline
\end{tabular}

Finally the cystographic pictures of the resting bladder and urethra were classified into three types (Fig. I): I. closed bladder neck; 2 . beak of contrast medium from partly open bladder neck into the posterior urethra; 3. open bladder neck and contrast filled posterior urethra down to the level of the external sphincter. No cystographic pictures were accepted for classification unless simultaneous intravesical pressure recording proved that the bladder was at rest.

The cystometric groups and the duration groups were correlated to the three cystographic types using a non-parametric correlation test (Spearman's test).

To obtain a classification involving both detrusor strength and duration of disease the patients' cystometric group number was multiplied with his duration group number. These pressure-duration scores ranging from I to 9 were also correlated to the cystographic types using a Spearman's test. 


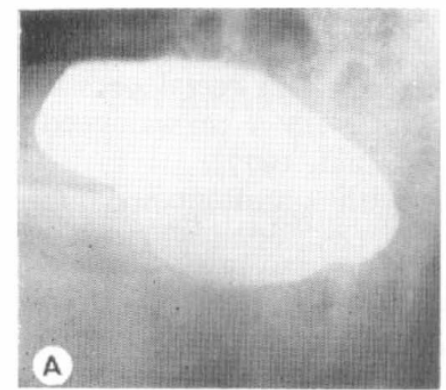

B
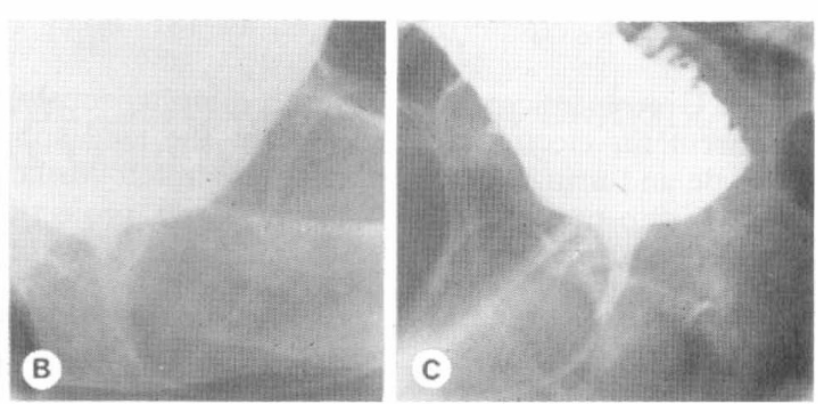

FIG. I

Cystourethrograms with the bladder at rest. A: Closed bladder neck. B: Beak of contrast in the posterior urethra. C: Wide open posterior urethra.

\section{Results}

Sixteen patients had a closed bladder neck and ten patients an open posterior urethra with the bladder at rest. The correlation to highest intravesical pressure at cystometry is shown in Figure 2. The correlation is statistically significant with $\mathrm{p}<0.02$.

The correlation between configuration of posterior urethra and duration of disease is shown in Figure 3. This correlation is not statistically significant $(p>0.05)$ although it can be seen that only two of I I patients investigated within the first 2 years after spinal cord injury had an open posterior urethra.

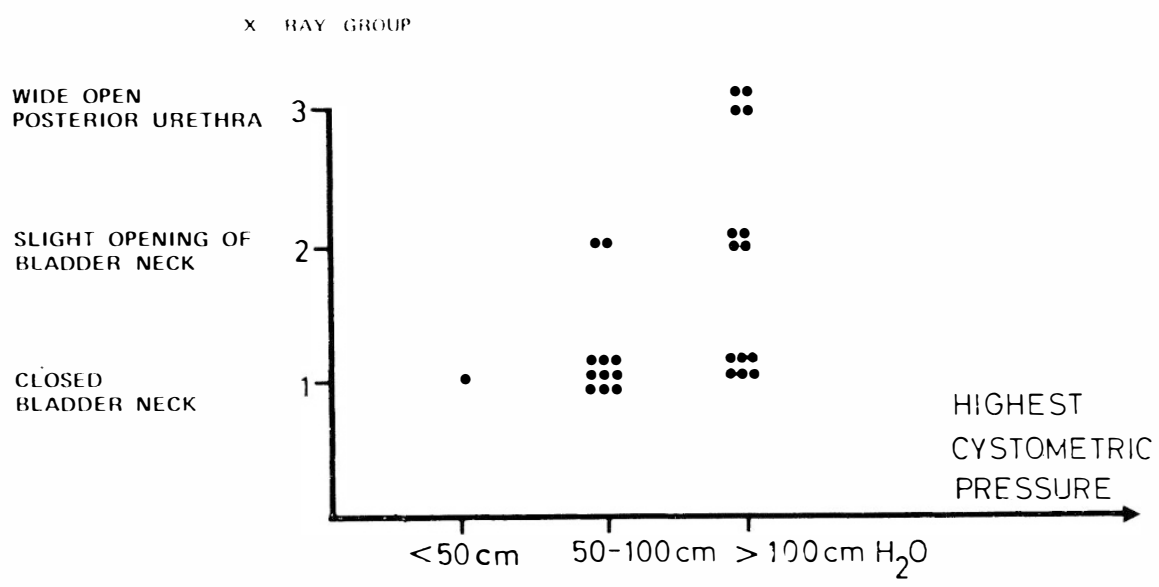

FIG. 2

Correlation between configuration of the resting posterior urethra at cystography and highest intravesical pressure during uninhibited detrusor contraction. (Spearman's rho $=0.5098$, $\mathrm{p}<0.02$.)

The correlation between configuration of posterior urethra and pressureduration score is shown in Figure 4. This correlation was also statistically signifi- 


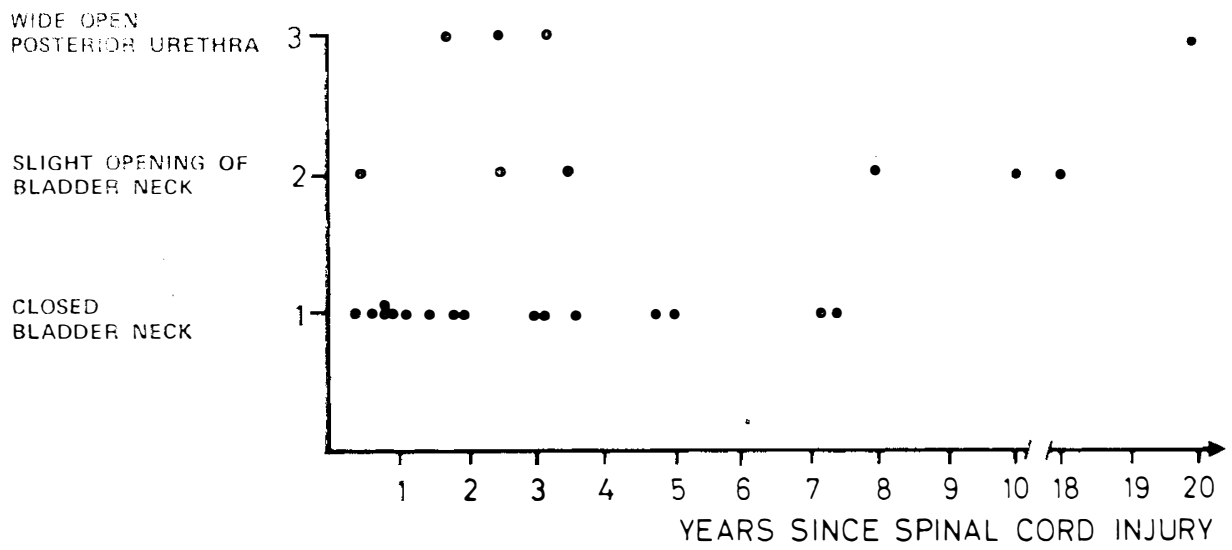

FIG. 3

Correlation between configuration of the resting posterior urethra at cystography and duration of disease since spinal cord injury. (Spearman's rho $=0.383 \mathrm{I}, \mathrm{p}>0.05$.)

$\times$ RAY GROUP

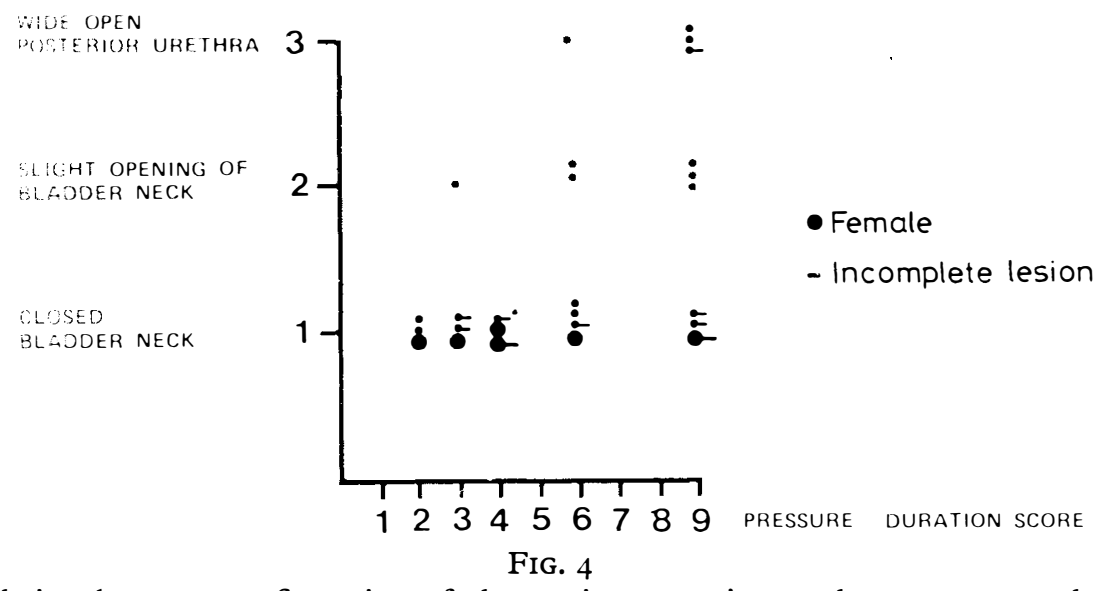

Correlation between configuration of the resting posterior urethra at cystography and pressure-duration score. (Spearman's rho $=0.5852, \mathrm{p}<0.01$.)

cant $(p<0.0$ ) with a higher correlation coefficient than between configuration of posterior urethra and highest cystometric pressure.

None of the six females in the material and only one with an incomplete spinal cord lesion had dilated posterior urethra with the bladder at rest (Fig. 4).

\section{Discussion}

In this series of patients with spinal cord injury and detrusor-sphincter dyssynergia a correlation has been found between increasing dilatation of the 
posterior urethra at rest and a high intravesical pressure during detrusor contraction, indicating that a strong detrusor muscle might be necessary to produce this widening of the posterior urethra.

The treatment of severe detrusor-sphincter dyssynergia is division of the external urethral sphincter (Malament, 1972; Gibbon, 1973; Perkash, 1976; Ross et al., I976; Morrow \& Bogaard, 1977). The rationale is that relief of obstruction with improved bladder emptying diminishes the risk of infection and or damage to the upper urinary tract.

Such sphincterotomies may cause erectile impotence (Schoenfeld et al., 1974) and are feared to cause or worsen incontinence. The impotence seems especially to occur after transurethral sphincterotomies at the 3 and 9 o'clock positions (Schoenfeld et al., I974) whereas sphincterotomies at the I and I I o'clock positions seem to be free from this complication (Kiviat, 1975). The literature, however, gives no specific reference to incontinence arising after sphincterotomy, perhaps because the patients were already incontinent before the operation or because incontinence was considered a minor problem in the context.

Dilatation of the posterior urethra is supposedly a factor leading to destruction of the upper urethral closure mechanism. Therefore, the importance of maintaining a normal posterior urethra is obvious since the posterior urethra will be the only structure to sustain continence when the distal urethral continence zone is destroyed by sphincterotomy. It is possible that early sphincterotomy within I or 2 years after spinal cord injury could prevent the development of a dilated bladder neck and posterior urethra, thereby decreasing the risk of making these patients severely incontinent after a sphincterotomy. One patient in this series with a wide open posterior urethra at rest had a transurethral sphincterotomy because of insufficient bladder emptying. Before the operation he was wearing an appliance because of occasional leak of urine, but after the operation he became totally incontinent with constant dripping and loss of large volumes of urine at the slightest straining.

That none of the females had a dilated posterior urethra at rest might be due to the lower urethral resistance in females making it easier for them to empty their bladder thereby diminishing the strain on the posterior urethra. Only one of the patients with incomplete spinal lesions had a dilated posterior urethra at rest. This might be due to the maintained bladder sensation in these patients making them able to feel when the bladder is almost filled up and that they consequently do not expose their posterior urethra to so severe strain by emptying before the onset of uninhibited detrusor contractions.

Summarising, it can be concluded that patients with spinal core lesions and detrusor-sphincter dyssynergia are in risk of developing a dilatation of the resting posterior urethra within the first years after injury. Women do not seem to run the same risk, or their risk is smaller, as well as the risk seems smaller in patients with incomplete spinal lesions.

\section{SUMMARY}

In 26 patients with detrusor-sphincter dyssynergia after a spinal cord injury the resting posterior urethra at cystography was found either closed as in normal subjects or open to a varying degree. Highest intravesical pressure measured at cystometry during uninhibited detrusor contraction was statistically significantly related to the degree of dilatation of the resting posterior urethra. An even higher correlation coefficient was found between the dilatation of the resting posterior 
urethra and an arbitrary score calculated on the basis of highest cystometric pressure and duration of disease since spinal cord injury. The possible importance of this finding in relation to incontinence after urethral sphincterotomy is discussed.

\section{RÉSUMÉ}

Chez 26 patients présentant après lésion médullaire une dyssynergie entre le sphincter vésical et le muscle detrusor, nous avons observé, lors de cystographie, que l'urèthre postérieur au repos était fermé comme chez les sujets normaux, ou bien ouvert, à des degrés divers.

La pression vésicale la plus élevée mesurée par cystométrie pendant la contraction non inhibité du detrusor vésical était en corrélation, statistiquement significative, avec le degré de dilatation de l'urèthre posterieur au repos. De plus, nous avons trouvé une corrélation encore plus significative entre la dilatation de l'urèthre postérieur au repos et un coefficient arbitraire calculé sur la base de la plus haute pression mesurée par cystométrie et sur la durée de la lésion spinale.

On discute ensuite l'importance de cette observation en relation avec l'incontinence attendue après sphinctérotomie uréthrale.

\section{ZUSAMMENFASSUNG}

26 Patienten mit Detrusor-Sphincter Dyssynergie nach Spinalläsionen hatten zystographisch einen geschlossenen Bläsenhals oder eine vielschichtige Insuffiiziens derselben. Der höchste intravesicale Druck, der nicht willkürlich beeinflussbaren Detrusorkontraktionen während der Zystometrie war mit dem Grad der Erweiterung der posterioren Hahnröhre statistisch signifikant verglichen.

\section{REFERENCES}

Frimodt-Møller, C. \& Hald, T. (1972). Clinical urodynamics. Scand. F. Urol. Nephrol., 6 (Suppl. I 5), I 43.

Gibbon, N. O. K. (I973). Division of the external sphincter. Brit. F. Urol., 45, I 10.

KIviat, M. D. (I975). Transurethral sphincterotomy: relationship of site of incision to postoperative potency and delayed haemorrhage. F. Urol., II4, 399.

MADERSBACHER, H. (1977). The neuropathic urethra: urethrogram and pathophysiologic aspects. Eur. Urol., 3, 32I.

MALAMENT, M. (1972). External sphincterotomy in neurogenic dysfunction. $\mathcal{F}$. Urol., 108, 554 .

MorRow, J. W. \& BogaARD, T. P. (I977). Bladder rehabilitation in patients with old spinal cord injuries with bladder neck incision and external sphincterotomy. F. Urol., II7, I64.

Nordling, J., Meyhoff, H. H., Walter, S. \& Andersen, J. T. (1978). Urethral electromyography using a new ring electrode. F. Urol., 120, 57 I.

Olesen, K. P. \& Walter, S. (1977). Colpo-cysto-urethrography. Dan. Med. Bull., 24, 96.

PERKASH, I. (1976). An attempt to understand and to treat voiding dysfunctions during rehabilitation of the bladder in spinal cord injury patients. F. Urol., 115, 36.

Ross, J. C., Gibbon, N. O. K. \& Sunder, G. S. (I976). Division of the external urethral sphincter in the neuropathic bladder: a twenty years' review. Brit. F. Urol., 48, 649.

Schoenfeld, L., Carrion, H. M. \& Politano, V. A. (1974). Erectile impotence. Complication of external sphincterotomy. Urology, 4, 68I. 